\title{
Anabases
}

ANABASES Traditions et réceptions de l'Antiquité

$27 \mid 2018$

Varia

\section{Cantabri aut vascones. La recepción de la Antigüedad en la cultura histórica vasca del siglo XIX}

Jonatan Pérez Mostazo

\section{(2) OpenEdition}

\section{Journals}

Edición electrónica

URL: http://journals.openedition.org/anabases/7160

DOI: 10.4000/anabases.7160

ISSN: 2256-9421

Editor

E.R.A.S.M.E.

Edición impresa

Fecha de publicación: 1 abril 2018

Paginación: 209-215

ISSN: 1774-4296

\section{Referencia electrónica}

Jonatan Pérez Mostazo, «Cantabri aut vascones. La recepción de la Antigüedad en la cultura histórica vasca del siglo XIX», Anabases [En línea], 27 | 2018, Puesto en línea el 01 abril 2020, consultado el 20 enero 2021. URL: http://journals.openedition.org/anabases/7160 ; DOI: https://doi.org/10.4000/ anabases. 7160 


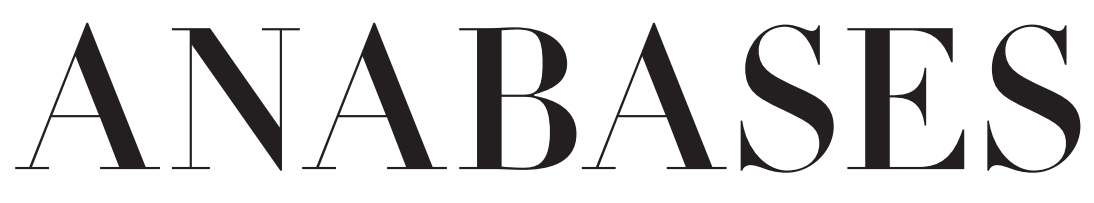

Traditions et Réceptions de l'Antiquité

$$
\begin{aligned}
& \text { No27 } \\
& 2018
\end{aligned}
$$

E.R.A.S.M.E.

Université Toulouse - Jean Jaurès 



\section{Sommaire}

$\mathrm{N}^{\circ} 27-2018$

\section{Historiographie et identités culturelles}

\section{Sébastien Cazalas}

“ et pour ce recite Valere... ». La place de l'Antiquité dans l'arsenal

intellectuel d'un grand prélat français du XVe siècle :

Jean Juvénal des Ursins (I388-I473) . . . . . . . . . . . . . . . . . . . II

Loic Marcou

La réception de l'Antiquité dans l'œuvre de la femme de lettres grecque

Rhéa Galanaki. . . . . . . . . . . . . . . . . . . . . .

\section{Traditions du patrimoine antique}

« Restituer Herculanum II. Des archives de fouilles aux restitutions 3D

Alexandra DARDENAY

Introduction : restituer l'espace domestique à Herculanum

grâce aux outils informatiques de reconstruction virtuelle ;

enjeux et problèmes. . . . . . . . . . . . . . . 4

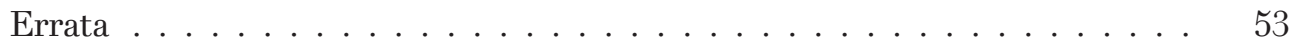

Carla Marotta

L’utilisation des données archivistiques dans l'enquête archéologique : nouvelles découvertes sur la maison d'Argos . . . . . . . . . . . . . . .

Emmanuelle Rosso

Restituer l'emplacement des statues dans les édifices d'Herculanum?

Problèmes de méthode . . . . . . . . . . . . . . . 7I 
Hélène Eristov, Marie-Laure Maraval

Restituer les décors perdus de la maison de Neptune et d'Amphitrite :

enquête, méthodes, résultats . . . . . . . . . . . . 9 9I

Maud Mulliez

Restauration numérique des peintures murales de la maison

de Neptune et Amphitrite à Herculanum : de l'expérimentation

matérielle à l'intégration des données dans un modèle 3D . . . . . . . Io3

\section{Archéologie des savoirs}

Nicolas SIRON

L'histoire de Philippidès d'Hérodote à Lucien.

Une incursion dans l'atelier du mythe . . . . . . . . . . . . . . . . Iog

Constantin Raios

Le coracin (xo@axîvos) du lac de Tibériade (F. Josèphe, B.J. III, 520) . . .

\section{Actualités et débats}

Claude Azıza

Antiquités parallèles (8). Le syndrome du sein droit . . . . . . . . . . . . I6I

Elisabeth DÉcultot

Winckelmann. Moderne Antike / Winckelmann. Modern Antiquity.

Exposition, Weimar, Neues Museum, 7 avril-2 juillet 20I7 . . . . . . . I67

\section{Lire, relire la bibliothèque des sciences de l'Antiquité}

Cyrielle LANDrea

Jérôme Carcopino et la mémoire perdue

de M. Valerius Messalla Corvinus (cos. 3г av. J.-C.) . . . . . . . . . . . . $\quad$ I77

Jérôme CARCopino

Notes biographiques sur M. Valerius Messala Corvinus . . . . . . . . . I I85

\section{L'atelier de l'histoire : chantiers historiographiques}

L'Atelier des doctorants (coordonné par Adeline Grand-Clément) (15)

Jonathan Pérez Mostazo

Cantabri aut vascones. La reception de la Antigüedad

en la cultura histórica vasca del siglo XIX . . . . . . . . . . . . . . . . . 209 


\section{Comptes rendus}

William H.F. Altman (éd.)

Brill's Companion to the Reception of Cicero (A. A. Raschieri). . . . . . . . 2 2I9

Anthony A. Barrett, Elaine Fantham, John C. Yardley

The Emperor Nero. A Guide to the Ancient Sources (É. Deniaux) . . . . . . 22I

Pascale Barthélémy et Violaine sébillotte cuchet (éd.)

Clio. Femmes, Genre, Histoire $\mathrm{n}^{\circ} 43$ : Citoyennetés (M. L. Napolitano) . . . 222

Frédéric Colin, Olivier Huck, Sylvie Vanseveren (éd.)

Interpretatio. Traduire l'altérité culturelle dans les civilisations

de l'Antiquité (Cl. Joncheray) . . . . . . . . . . . . . . . . . . . . 224

Angus Fletcher

Comic Democracies. From Ancient Athens

to the American Republic (A. de Crémoux). . . . . . . . . . . . . . . . . . 226

David Hernández de la Fuente

El despertar del alma. Dioniso y Ariadna: mito y misterio (A. Iriarte) . . . . 228

Ted Kaizer (éd.)

Religion, Society and Culture at Dura-Europos (P. G. Michelotto) . . . . . 229

Jacques Le Goff, Jean-Pierre Vernant

Dialogue sur l'histoire. Entretiens avec Emmanuel Laurentin (C. Lucci). . 23I

Justine Mac Connell, Edith Hall

Ancient Greek Myth in World Fiction since ig8g (A. de Crémoux) . . . . . . 233

Angelo Mazzocco, Marc Laureys (éd.)

ANew Sense of the Past. The Scholarship

of Biondo Flavio (I3g2-I463) (C. Lucci). . . . . . . . . . . . . . . . . . . . . . 234

Seth L. Schein

Homeric Epic and Its Reception. Interpretative Essays (S. Sistac) . . . . . . 236

Arbogast SснмiтT

Wie aufgeklärt ist die Vernunft der Aufklärung?

Eine Kritik aus aristotelischer Sicht (L. Calvié) . . . . . . . . . . . . . . . . 238

Richard Sorabu (éd.)

Aristotle Re-Interpreted. New Findings on Seven Hundred Years

of the Ancient Commentators (P. Butti de Lima) . . . . . . . . . . . . . . . 239

Laura SwiFT

Greek Tragedy. Themes and Contexts (G. Aujac) . . . . . . . . . . . . . . 24

Zara Martirosova TorLone

Vergil in Russia. National Identity and Classical Reception

(D. Millet-Gérard) . . . . . . . . . . . . . . . . . . 243 
Jürgen von UNGERN-STERNBERG

Les chers ennemis. Deutsche und französische

Altertumswissenschaftler in Rivalität und Zusammenarbeit (L. Calvié) . . 2444

Robert W. WALLACE

Reconstructing Damon: Music, Wisdom Teaching, and Politics

in Perikles'Athens (A. Brancacci) . . . . . . . . . . . . . . . . . . . . . 246

T. P. Wiseman

The Roman Audience : Classical Literature as Social History (C. Landrea) 249

Résumés . . . . . . . . . . . . . . . . . . . . . . . . . . 253

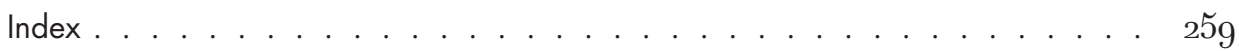




\section{L'atelier de l'histoire :}

chantiers historiographiques 

Anabases 27 (2018), p. 209-215.

\section{L'Atelier des doctorants}

\section{Cantabri aut vascones. \\ La recepción de la Antigüedad en la cultura histórica vasca del siglo XIX}

\section{Jonatan Pérez Mostazo}

En el año 20Io, la dirección del Partido Nacionalista Vasco sorprendió a la opinión pública al participar en los carnavales caracterizados como los personajes de la aldea gala de Astérix y Obélix. Hacía menos de un año desde que un partido no nacionalista había accedido al gobierno autonómico y el PNV vio en los célebres galos un modo de reivindicar, desde el humor y la sátira, la defensa de lo autóctono (nacionalistas-galos) frente a la amenaza exterior (no nacionalistas-romanos). Conectaba, así, consciente o inconscientemente, con una tradición historiográfica secular en la que la oposición a Roma había sido uno de los motivos más recurrentes. La erudición autóctona de esta comunidad radicada a ambos lados de los Pirineos occidentales, entre los ríos Adur y Ebro, construyó desde inicios de la Modernidad un discurso en torno a la peculiaridad y excelencia vascas, basada en una lengua diferente a todas las que le rodeaban, pero también a unos orígenes y una historia antigua que consideraban excepcional. Los ecos de aquella visión del pasado seguían resonando en los trajes y discursos de aquella velada festiva.

La investigación doctoral que se $\operatorname{presenta}^{1}$ pretende analizar la recepción y apropiación política e identitaria de la Antigüedad en la sociedad vasca durante el siglo XIX. El fenómeno, como se ha visto, ha sido una constante hasta fechas muy recientes. Pero lejos de constituir una particularidad vasca, el uso y abuso de la historia antigua se han manifestado en muchos espacios europeos y circunmediterráneos, como lo vienen mostrando multitud de publicaciones, equipos de investigación y encuentros científicos ${ }^{2}$.

1 Cantabri aut vascones. La recepción de la Antigüedad en la cultura histórica vasca del siglo XIX, realizada en el Programa de Doctorado Interuniversitario en Ciencias de la Antigüedad de la Universidad del País Vasco-Euskal Herriko Unibertsitatea, bajo la dirección de Antonio Duplá Ansuategui, con una ayuda predoctoral FPU del Ministerio de Educación, Cultura y Deporte del Gobierno de España.

2 Sin pretensión de ser exhaustivos, se pueden mencionar A. DE Francesco (ed.), In Search of Pre-Classical Antiquity: Rediscovering Ancient Peoples in Mediterranean

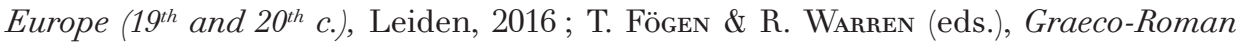


Durante los meses de abril, mayo y junio de 2017 realicé una estancia en el Equipo de Investigación PLH-ERASME para introducir nuevos elementos de análisis en el caso vasco, contextualizando la producción cultural e historiográfica vasca en la europea de su misma época. Las líneas que continúan son, en buena medida, consecuencia de la presentación de la investigación que realicé en el Equipo ${ }^{3}$.

Como tantas otras sociedades a lo largo de la historia, los vascos aspiraron a establecer un diálogo con la Antigüedad para responder a cuestiones políticas e identitarias modernas. Aquella relación bidireccional entre pasado y presente está en el centro de interés de nuestro estudio. El pasado seleccionado ha sido la Antigüedad clásica y protohistórica, aunque no en su totalidad, sino exclusivamente aquella que los vascos han creído protagonizada por sus ancestros : a grandes rasgos, la referida a los grupos de población que las fuentes greco-latinas sitúan entre el Ebro, el Océano Atlántico y el Pirineo occidental, especialmente los cántabros y vascones. El "presente" escogido se refiere al País Vasco del sur de los Pirineos durante el siglo XIX, teniendo en cuenta también el contexto hispánico en el que se inserta. La época seleccionada comienza en i795, final de la Guerra contra la República Francesa, y concluye a la vez que el siglo, en igoo. En este periodo, la sociedad vasca transitó del Antiguo Régimen al Estado liberal, creando además cierta identidad etno-regional de la que se alimentó el nacionalismo vasco a finales de la centuria.

El diálogo con el pasado antiguo tuvo, sin embargo, sus limitaciones. Como toda época pasada, la Antigüedad no era un objeto tangible ni un lugar determinado, no era aprehensible mediante los sentidos y por lo tanto no podía conocerse de manera directa. Hacía tiempo que había dejado de existir y solo podía traerse al presente a través de los testimonios que habían sobrevivido al paso de los siglos, después de un proceso cognitivo de interpretación y síntesis ${ }^{4}$. El resultado fueron las diversas representaciones del pasado

Antiquity and the Idea of Nationalism in the $19^{\text {th }}$ Century. Case Studies, Berlin \& Boston, 2016 ; J. Bassi \& G. CANÈ (eds.), Sulle spalle degli antichi. Eredità classica e costruzione delle identità nazionali nel Novecento, Milano, 2014; G. Kuaniczay, M. Werner \& O. Gecser (eds.), Multiple Antiquities - Multiple Modernities. Ancient Histories in Nineteenth Century Europeans Cultures, Frankfurt \& New York, 2011. Entre los números de revista dedicados monográficamente al tema, el no 27, vol. 2 de Archaeological Review from Cambridge (2012), titulado Archaeology and the (De)Construction of National and Supra-National Polities y el n ${ }^{\circ} 1$ de Anabases (2005), titulado La Nation et l'Antiquité. Entre los proyectos de Investigación, se puede destacar el que acoge la tesis doctoral que se presenta, el Proyecto ANIHO Antigüedad, nacionalismos e identidades complejas en la historiografía occidental (1789-1989): Aproximaciones desde Europa y América Latina (MINECO HAR2016-76940-P).

3 A gradezco a los miembros del equipo la oportunidad de presentar mi proyecto de tesis en aquella ocasión, así como la invitación a publicarlo en la revista Anabases. También agradezco a todos los investigadores que hicieron aquella estancia enriquecedora tanto en lo académico como en lo personal.

4 F. Sánchez Costa, “ La fragua de la identidad: Memoria, conciencia histórica y cultura histórica ", in F. Sánchez Costa \& J. L. Palos (eds.), A vueltas con el pasado. Historia, memoria y vida, Barcelona, 2013, p. 185-211 ; F. SÁnchez Costa, “ La cultura histórica: 
que constituyen nuestro objeto de estudio. Este diálogo estuvo mediatizado por una compleja red de relaciones entre contextos presentes, realidades pasadas y medios para acceder a ellas, presentando numerosos interrogantes. En primer lugar, qué influencia pudieron ejercer las representaciones del pasado antiguo en el contexto vasco del siglo XIX, concretamente en los discursos políticos e identitarios. En segundo lugar, qué relaciones se establecieron en sentido contrario, esto es, entre los preconceptos políticos e identitarios de la época y las recreaciones de la Antigüedad. Finalmente, qué papel jugaron la evidencia histórica o las fuentes y sus interpretaciones en esta relación bidireccional.

El primer reto ha sido definir de la cultura histórica del contexto seleccionado. Durante los siglos XVI-XVIII fueron los cronistas, tratadistas y juristas quienes por encargo de diversas instituciones, o buscando la mayor gloria de su provincia, fueron elaborando la imagen canónica del pasado vasco ${ }^{5}$. Sin embargo, la modernización del siglo XIX tuvo como consecuencia la multiplicación de los centros de producción cultural, de sus medios de difusión y del público receptor ${ }^{6}$. Para el análisis de esta compleja realidad, hemos adoptado los presupuestos de los estudios de la cultura histórica, que aborda los fenómenos sociales y culturales que desembocan en la producción de representaciones del pasado desde una perspectiva global ${ }^{7}$. Por un lado, se han tenido en cuenta todas aquellas referencias al pasado que fueron tenidas por verdaderas por sus contemporáneos ${ }^{8}$, primase en ellas la dimensión política, la estética o la cognitiva. Por el otro, se han intentado definir todos los elementos que toman parte en la generación de la cultura histórica, desde los productores y sus círculos de socialización, a los mensajes que emitieron, los medios que para ello utilizaron y la acogida que tuvieron entre el público.

Así, se han podido establecer tres fases a lo largo del siglo. Durante la primera, que abarca las últimas décadas del absolutismo en España (I795-I833), fueron los ilustrados

una aproximación diferente a la memoria colectiva ", Pasado y Memoria: Revista de Historia Contemporánea 8 (2009), p. 267-286; D. Lowenthal, The Past is a Foreign Country, Cambridge \& New York, 1985.

5 M. Montero \& F. García de Cortázar, “ Historiografía », in M. Montero \& F. García de Cortázar (eds.), Diccionario de Historia del País Vasco, Donostia-San Sebastián, 1983, p. 402-444; A. E. Mañaricua, Historiografía de Vizcaya. Desde Lope García de Salazar a Labayru, Bilbao, 1971.

6 M. Goynenetche, Les Basques et leur histoire, Baiona \& Donostia-San Sebastián, 1993 ; J. M. SÁnchez-Prieto, El imaginario vasco. Representaciones de una conciencia histórica, nacional y política en el escenario europeo 1833-1876, Barcelona, 1993.

7 Sánchez Costa, “Fragua »; SÁnchez Costa, "Cultura »; M. Grever, “ Fear of Plurality: Historical Culture and Historiographical Canonization in Western Europe ", in A. Epple \& A. Schaser (eds.), Gendering historiography: beyond national canons, Frankfurt \& New York, 2009, p. 45-62 ; J. RüsEN, “ Was ist Geschichtskultur? Überlegungen zu einer Art, über Geschichte nachzudenken », in K. Füssmann, H. T. GrütTER, \& J. RüsEn (eds.), Historische Faszination. Geschichtskultur heute, Keulen, Weimar \& Wenen, 1994, p. 3-26.

8 Definición tomada de C.-O. Carbonell, “ Pour une histoire de l'historiographie », Storia della Storiografia 1 (1982), p. 7-25. 
vinculados a la desaparecida Sociedad Bascongada o los juristas al servicio de las instituciones forales quienes dominaron la producción historiográfica, aunque la incipiente prensa surgió como un nuevo espacio de creación de imágenes sobre la Antigüedad. Con el establecimiento definitivo del Estado liberal (I833) y hasta el inicio de la última Guerra Carlista (I872), se fue desarrollando una nueva historiografía provincial al calor del Romanticismo, difundida en revistas pintorescas y libros de historia por eruditos y hombres políticos que recibieron en ocasiones el apoyo de las instituciones forales y se reunieron a menudo en sociedades literarias privadas como los ateneos. Un momento en el que la Antigüedad fue frecuentemente evocada en ensayos y discursos de carácter político, en defensa de la identidad vasca y sus instituciones particulares, los fueros. En la última fase, que coincide con las primeras décadas de la Restauración borbónica (I875-1900), la cultura vasca conoció un auge de mano del regionalismo vasquista, lo que trajo la aparición de nuevos espacios de producción cultural, como los certámenes literarios de los Juegos Florales. Pero también se conoció una consolidación de las Comisiones Provinciales de Monumentos, formadas por correspondientes de las Reales Academias, que progresivamente acogieron a catedráticos de instituto, cronistas y archiveros, posibilitando así las primeras muestras de profesionalización y positivismo en la historiografía vasca.

Una vez definido el contexto, ha sido necesario identificar el papel que la Antigüedad jugó en los discursos políticos e identitarios del siglo XIX. La investigación señaló hace tiempo la alta politización de la historiografía vasca hasta fechas recientes ${ }^{9}$. Respecto a la Antigüedad, estos mismos estudios identificaron una serie de tópicos o mitos historiográficos que estructuraban su visión canónica y que respondían a los intereses de las instituciones que los promocionaban ${ }^{10}$. Para los autores del siglo XVI, XVII y XVIII como Garibay, Henao, Larramendi o Fontecha Salazar, los vascos habrían sido los primeros pobladores de la Península Ibérica, conocidos por las fuentes clásicas como iberos, cuya lengua, el euskera, habría sido la primitiva de todos los españoles (vascoiberismo). Además, gracias a la secular oposición a los extranjeros de los cántabros, identificados como ancestros de los vascos, se habrían mantenido puros, sin mezcla e independientes durante las diversas invasiones y conquistas que, como la romana, había sufrido la Península (vascocantabrismo). Como pueblo de orígenes bíblicos, habrían conservado también la creencia en un solo dios verdadero hasta la adopción definitiva del cristianismo (monoteísmo primitivo). Estos mitos sufrieron la crítica de la erudición ilustrada durante el siglo XVIII, pero siguieron manteniéndose durante buena parte del siglo XIX, debido en cierta medida a la dimensión política e identitaria que se les había concedido.

La investigación propuesta aspira a comprender esta dimensión política e identitaria de la Antigüedad para el caso vasco. Pero para ello hemos visto necesario ir más allá de los mitos historiográficos mencionados. Diversos estudios han mostrado cómo estos siguieron siendo sometidos a la crítica durante las primeras décadas del siglo, especialmente por la Real Academia de la Historia en su Diccionario Geográfico-Histórico de I8o2 o por histo-

9 M. Montero, “ La invención del pasado en la tradición historiográfica vasca », Historia Contemporánea 7 (1992), p. 283-294.

10 Mañaricua, Historiografía. 
riadores cercanos a la Corte, como Juan Antonio Llorente ${ }^{11}$. También se ha destacado el papel que jugaron como elemento de la nueva identidad vascongada elaborada por la élite política, cultural y religiosa de las Provincias Vascas durante buena parte del siglo XIX, así como su acomodo a la literatura histórico-legendaria del momento o su pervivencia en la historiografía ${ }^{12}$. Sin embargo, vemos necesario adoptar una perspectiva alternativa que permita contextualizar los acercamientos a la historia antigua de los vascos dentro del espacio europeo. Es por ello que nos hemos centrado en las principales problemáticas y cuestiones a las que intentaron responder los autores vascos cuando escribían sobre el pasado antiguo de sus ancestros, observando que no fueron tan diferentes a las que presidieron la historiografía del resto del continente.

La primera preocupación fue la identificación de los ancestros entre los pueblos citados por las fuentes antiguas y la determinación de su territorio. Desde la Edad Media los diferentes espacios étnicos y políticos que se constituyeron en el solar del Imperio Romano buscaron los primeros miembros de sus comunidades o linajes en diferentes referentes de prestigio, como la tradición bíblica, la homérica o la greco-latina ${ }^{13}$. Este fue un proceso que continuó en durante el siglo XIX, momento de formación de las identidades nacionales, y el País Vasco no supuso una excepción. Reivindicándose herederos del patriarca bíblico Túbal durante buena parte de la centuria, para época protohistórica se identificaron principalmente con los cántabros y los vascones. Estos últimos habían sido tradicionalmente considerados como ancestros de los navarros, pero para finales de siglo se recuperó la hipótesis de Arnaut d'Ohinart, autor vasco-francés del siglo XVII, que hacía a todos los vascos descendientes de esta comunidad protohistórica. Esta idea terminó por imponerse mayoritariamente, relegando a unos cántabros cuyo territorio antiguo se extendía mucho más al oeste que el actual territorio vasco.

En segundo lugar, los autores vascos también trataron de definir las primeras glorias y héroes de su comunidad, al modo de los panteones de héroes patrios de las naciones europeas, popularizados durante el siglo XIX, que comenzaron a menudo por líderes indígenas opuestos al imperialismo romano y mártires perecidos en heroicas derrotas ante el invasor. También los vascos buscaron estos episodios en las fuentes clásicas, especialmente en las Guerras Cántabras contra Augusto o en el asedio de la ciudad de Calahorra por las tropas pompeyanas. En ocasiones, estas hazañas sirvieron para mostrar los servicios prestados a la defensa de la nación o el protagonismo de los vascos en la historia nacional. Pero en

1 J. M. Pontillo, Monarquía y gobierno provincial. Poder y Constitución en las Provincias Vascas (1760-1808), Madrid, 1991 ; MaÑaricua, Historiografía.

12 C. Rubio, La identidad vasca en el siglo XIX. Discurso y agentes sociales, Madrid, 2003 ; J. JuARIsti, El linaje de Aitor. La invención de la tradición vasca, Madrid, 1987 ; SÁnchez Prieto, Imaginario; Goyhenetche, Basques ; A. Emborujo, « El País Vasco en la Antigüedad: Antonio de Trueba, un ejemplo de la corriente historiográfica Fuerista, Veleia 8 (1991), p. 483-492 ; A. Duplá \& A. Emborujo, “ El Vascocantabrismo: mito y realidad en la historiografía sobre el País Vasco en la Antigüedad », in J. Arce \& R. Olmos (eds.), Historiografía de la Arqueología y de la Historia Antigua en España (siglos XVIII-XIX), Madrid, 1991, p. 107-111.

13 J. Juaristi, El bosque originario, Madrid, 2000. 
otros casos, los episodios se mostraron como mérito exclusivo de la comunidad que los había protagonizado, como elemento de prestigio local o regional que oponer a la cultura histórica nacional hegemónica.

En tercer lugar, hubo intensos debates sobre la relación de sumisión o independencia establecida con Roma. La erudición vasca prefirió ilustrar a sus ancestros libres de toda dominación romana, conservado íntegramente su independencia. Sin embargo, con el transcurso del siglo tuvo que ir corrigiendo sus pretensiones. Por un lado, por la proliferación de los hallazgos arqueológicos de época romana en el territorio vasco. Por el otro, para contrarrestar las acusaciones de barbarismo que, especialmente a partir de los años 7o, comenzaron a proliferar en la publicística nacionalista española. La independencia respecto a Roma podía suponer un orgullo, pero también ser interpretada como un secular aislamiento de las corrientes civilizatorias de las que los Estados liberales de la época del imperialismo se reclamaron herederos ${ }^{14}$.

En cuarto y último lugar, hubo una especial preocupación por definir las esencias, virtudes y defectos originales de los vascos, y hasta qué punto estos se habían perdido y en qué medida hacía falta recuperarlos. Los políticos, historiadores y literatos vascos reivindicaron durante buena parte del siglo la conservación de una lengua, unas leyes y una raza que hundían su origen en la noche de los tiempos. Estos elementos, junto al carácter belicoso, el amor a la libertad y el más profundo patriotismo, formaron una imagen prestigiosa de los vascos como últimos representantes de la esencia hispana. Pero, como ya se ha visto, la pretendida antigüedad del carácter vasco también sirvió en contextos de confrontación para mostrarlos como un reducto de barbarie opuesto a la ley del progreso al que el Estado liberal debía civilizar. En un siglo XIX dominado por el peso del pasado, fueron numerosas las publicaciones europeas que intentaron responder estos mismos interrogantes en torno a las esencias patrias.

Volviendo a los objetivos planteados, se pretende en último lugar comprender el papel que jugaron los testimonios históricos y sus diversas interpretaciones en el complejo diálogo entre las representaciones del pasado y los contextos presentes. Algunos estudios sobre historia de la arqueología vasca han analizado la relación entre las ideologías dominantes y la interpretación de los restos materiales ${ }^{15}$. Sin embargo, para las representaciones del pasado antiguo fundamentadas en las fuentes clásicas, estas han sido mayoritariamente ignoradas. Es por ello que hemos adoptado los presupuestos teóricos de la Recepción Clásica para definir la relevancia de los escritos de autores grecolatinos como Estrabón, Plinio, Ptolomeo, Silio Itálico, Floro o Dion Casio en las imágenes generadas en torno al pasado antiguo de los vascos. Entendemos así que los textos, restos materiales y prácticas que han sobrevivido a la Antigüedad no tienen un significado definido ni definitivo, sino que son reinterpretados por los lectores de cada época. Estas lecturas están condicionadas por el horizonte de expectativas del lector, aunque si quieren

14 F. Molina Aparicio, La tierra del martirio español. El País Vasco y España en el siglo del nacionalismo, Madrid, 2005.

15 C. Ortiz de Urbina, El desarrollo de la Arqueología en Álava: condicionantes y conquistas (siglos XVIII-XIX), Vitoria, 1996 ; K. LARraÑaGA, "Vascocantabrismo y arqueología », Memorias de Historia Antigua 19-20 (1999), p. 111-198. 
ser verosímiles no pueden escapar al texto, que establece sus propios límites. Así, el proceso de recepción de la Antigüedad nos habla de un diálogo bidireccional entre las fuentes antiguas y lector moderno que aspira a comprenderlas para utilizarlas ${ }^{16}$. Sin duda, este fenómeno se dio también en el caso vasco, aunque todavía no se ha profundizado en su estudio, salvo contribuciones puntuales.

Mediante la combinación de estas perspectivas metodológicas y teóricas pretendemos dar respuesta, desde las Ciencias de la Antigüedad, a los interrogantes que sigue planteando el diálogo que los agentes políticos y culturales vascos intentaron establecer con el pasado más antiguo de su comunidad. Esperamos, así, propiciar nuevas perspectivas de estudio de las fuentes greco-latinas referentes a este territorio; pero, sobre todo, dilucidar qué procesos históricos han llevado a que la Antigüedad siga siendo un referente operativo en el imaginario político e identitario de los vascos. Hasta tal punto que todavía hoy los dirigentes del nacionalismo vasco deciden ponerse en la piel de Astéix, Obélix y sus compañeros de batallas para lanzar un mensaje de gran simbolismo.

\section{Jonatan Pérez Mostazo}

Universidad del País Vasco

Euskal Herriko Unibertsitatea

Departamento de Estudios Clásicos,

C/ Tomás y Valiente $\mathrm{s} / \mathrm{n}$,

01006 Vitoria-Gasteiz (España)

jonatannicolas.perez@ehu.eus

16 P. PAyen, “L'Antiquité et ses réceptions: un nouvel objet d'histoire », Anabases 10 (2009), p. 9-23 ; L. Hardwick \& C. Stray, A Companion to Classical Receptions, Oxford, 2008 ; C. W. Kallendorf (ed.), A Companion to the Classical Tradition, Malden, 2007 ; C. Martindale, Redeeming the Text. Latin Poetry and the Hermeneutics of Reception, Cambridge, 1993. 
